\section{Public science, private profits}

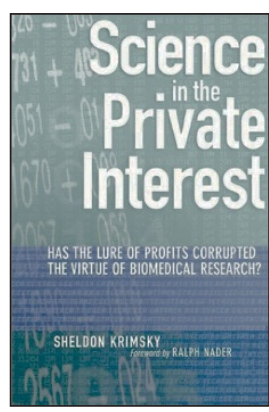

\section{Science in the Private Interest: Has the Lure of Profits Corrupted Biomedical Research?}

\section{By Sheldon Krimsky}

Rowman \& Littlefield Publishers, 2003

264 pp. cloth, $\$ 27.95$

ISBN 074251479X

\section{Reviewed by Zach W Hall}

Is the university selling its soul to balance its books? From college athletics, to education for profit, to patent litigation, to clinical trials, universities seem to be busy making deals in the marketplace that challenge our traditional view of the university as ivory tower. In response, a stream of books, symposia and news stories have questioned whether the university's mission is being corrupted by commercial values.

Sheldon Krimsky's new book, Science in the Private Interest, addresses this question with respect to biomedical research. Although its discussion extends beyond universities, the principal focus of the book is the danger to academic values that results from commercial entanglement. The rise of the biotech industry, the passage of the Bayh-Dole Act in 1980 and the explosive growth of clinical trials sponsored by the pharmaceutical industry have all contributed to a rapid increase in university-industry interactions over the last two decades. This has posed new challenges for universities, which have struggled to adapt their policies to keep up with the changing times.

The publication of a book examining these issues in detail is thus timely and welcome. A major strength of Krimsky's book is its comprehensive account of problems that have arisen from the 'partnership' of academia and industry. Although many of the incidents have been well publicized, the book is a valuable resource for those who have not followed these events closely. Krimsky reviews a number of scholarly studies detailing the increased involvement of university faculty with private companies and the failure of current policies to prevent abuses. Separate chapters discuss issues related to federal advisory committees and scientific journals.

Although the book is successful as an indictment of poor practices, it is less successful in providing a thoughtful and constructive frame-

Zach Hall is at the Keck School of Medicine of the University of Southern California, 1975 Zonal Avenue, KAM-110, Los Angeles, California 90033, USA. He has also served as President and CEO of EnVivo Pharmaceuticals, and as Vice Chancellor at University of California, San Francisco, where he was responsible for technology transfer.

e-mail: zhall@usc.edu work for solving the problems that it so thoroughly documents. Krimsky's view of the problem is far too simplistic, bordering on the ideological. For him, any involvement of universities with industry inevitably leads to a corruption of values. The book thus exudes an air of deep lamentation; in Krimsky's view, it seems, we have fallen from a state of grace, as the mission of universities has become undermined by contact with industry.

Krimsky frames the loss to universities in a curious and idiosyncratic way. According to his formulation, the rise of science in the private interest has directly and inevitably led to a decline of science in the public interest. What is science in the public interest? Krimsky emphasizes preventive medicine, social policy research and the capacity to give disinterested advice to the public on scientific matters. As important as these are, however, they represent only a small subset of the benefits that universities can offer to society. Advancing knowledge and making that knowledge available for the public good are also key parts of the university's mission. Unfortunately, the book never addresses the general problem of how academic discoveries in the life sciences can be translated into improvements in human health. To achieve this aim in our society, universities and industry must interact. As modern biology has become more collaborative and as more scientific innovation occurs in private companies, academy-industry partnerships also become driven by scientific needs. The question then becomes not whether to engage with industry, but how to do it on terms that preserve academic values.

The book also oversimplifies the motivations of faculty members, which Krimsky seems to see in purely economic terms. In fact, most of the scientists who are engaged with industry are highly successful academic researchers with strong government support. Although not insensible to the economic advantages of working with industry, most are deeply gratified by the idea that their work might have practical benefit and are eager to help bring this about. Many participate only peripherally, serving on advisory boards or as occasional consultants. Others start companies (as I have done). The problems raised by these two activities are quite different, as are the problems of basic and clinical scientists, but these are rarely distinguished in the book's discussions.

If the partnership is worth preserving, how can its problems be addressed? Universities need to agree upon a uniform code regulating conflict of interest that can be easily applied and easily understood by the public. Universities need to develop effective mechanisms to track conflicts of interest and to deal with them when they arise. Journals (including this one) need to participate in the effort to prevent abuses by insisting on disclosure of financial interests and by having firm rules to prohibit 'ghost' authorship. The Bayh-Dole Act needs to be amended to allow easier exchange of materials for research. Clinical societies need to establish codes of conduct that clearly separate clinical trial researchers from any financial connection with the sponsor or any company that stands to benefit from the trial. By illustrating the problems that arise, Krimsky's book gives us a start. What we need next is informed, thoughtful discussion by those who understand the process, the practitioners and the institutions, and who are also committed, in the broadest sense, to science in the public interest. 